\title{
A Graduação na Pesquisa em Educação (Anped 1996-2003)
}

\section{The higher education in education research field (ANPED 1996-2003)}

\section{Clara Brener Mindal'}

\section{Resumo:}

Neste artigo apresentamos resultados de pesquisa (do tipo documental bibliográfica) desenvolvida entre 2003 e 2006, cujo objetivo foi realizar um mapeamento dos aspectos abordados nos estudos sobre a graduação nos trabalhos apresentados nas reuniões anuais da Associação Nacional de Pesquisa e Pós-Graduação em Educação - ANPEd - no período entre 1996 e 2003. Foram analisados 163 trabalhos e os dados coletados foram comparados com análises da produção científica brasileira sobre ensino superior. Os resultados mostram pesquisa em ascensão mais ainda incipiente em relação a outros temas veiculados na ANPEd; ênfase maior ao estudo de cursos, disciplinas, processos de ensinoaprendizagem e outros temas ligados aos cursos de licenciatura, em especial pedagogia e matemática. Alguns aspectos são pouco ou nada estudados, entre eles, o de pesquisa sobre os alunos de graduação, o da qualidade e condições de trabalho dos professores.

Palavras-Chave: ensino superior, produção acadêmica; ANPEd.

\begin{abstract}
:
In this article we present ourselves when we resulted from inquiry (of the documentary type bibliographical) developed between 2003 and 2006, whose objective carried out a mapeamento of the aspects boarded in the studies on the graduation in the works presented in the annual meetings of the National Association of Inquiry and Postgraduation in Education - ANPEd in the period between 1996 and 2003. 163 works were analysed and the collected data were compared with analyses of the scientific Brazilian production on superior teaching. The results show inquiry in ascent more still incipient regarding other subjects conveyed in the ANPEd; bigger emphasis to the study of courses, disciplines, processes of teachingapprenticeship and other subjects connected with the courses of degree course, in special pedagogy and mathematics. Some aspects are little or not studied at all, between them, it of inquiry on the pupils of graduation, it of the quality and conditions of work of the teachers.

Key-words: Higher Education; Academic production; ANPEd.
\end{abstract}

'Professora do Departamento de Teoria e Fundamentos da Educação/Setor de Educação. clarabrenermindal@ufpr.br. 
Neste artigo apresentamos resultados de pesquisa (do tipo Estado da Arte) desenvolvida entre 2003 e 2006, cujo objetivo foi realizar um mapeamento de produção científica e nele desvelar o que os trabalhos apresentados nas reuniões anuais da Associação Nacional de Pesquisa e Pós-Graduação em Educação ANPEd - nos diziam sobre a graduação.

Por que a graduação? Por que a ANPEd? A escolha da graduação como objeto de pesquisa surgiu da preocupação com a qualidade do ensino e da aprendizagem nesse nível. Como professora de Psicologia da Educação em cursos de licenciatura, vinha questionando o trabalho realizado; ao mesmo tempo, buscava uma compreensão do papel e dos rumos que esse nível de educação tomava no âmbito da universidade e do ensino superior no Brasil. $\mathrm{Na}$ busca de respostas às minhas interrogações voltei-me para a produção científica na área de educação. Escolhi pesquisar a produção científica veiculada na ANPEd porque este é o evento de debate e de divulgação de pesquisa, na área da educação, de maior prestígio nacional. O período escolhido inicia em 1996, ano de definição da Lei de Diretrizes e Bases para a Educação Nacional - LDBEN/ 96 e termina em 2003, início da coleta de dados que culminou em nossa tese de doutoramento. ${ }^{2}$
Nos oito anos desse período, foram realizadas oito reuniões anuais e apresentados na ANPEd 1.985 trabalhos. Para nossa pesquisa excluímos os trabalhos excedentes, de mesas redondas, encomendados e pôsteres; estes últimos por apresentarem, geralmente, pesquisas em andamento e os primeiros, porque nem todos tinham texto disponível. Dototal de 1.985 trabalhos apresentados foram, então, considerados 1.174 e destes analisados 163 .

Quanto à modalidade de curso, em 35\% dos 163 textos, encontramos referências aos cursos de licenciatura; em $7 \%$ referências aos cursos de bacharelado e em $9 \%$ encontramos discussões sobre aspectos de ambas as modalidades de curso: bacharelado e licenciatura. Em 29\% dos textos analisados, os autores discutem questões relativas ao ensino superior em geral, tais como: políticas para o ensino superior, financiamento, autonomia, entre outras, com implicações para todas as modalidades e níveis, graduação e pós-graduação. A graduação é discutida em 19\% dos trabalhos e a relação deste nível com a pós-graduação é apenas abordada em 1\% dos trabalhos.

Pesquisase discussõesteóricassobreestrutura curricular, os cursos e as disciplinas específicas, as práticas pedagógicas, os processos de ensino - aprendizagem, as diversas concepções

2MINDAL. C. B. M. A graduação nos trabalhos da ANPEd (1996 - 2003). Tese de Doutorado defendida em 2006 , junto ao Programa de Estudos Pós-Graduados, Pós-Graduação em Educação: Psicologia da Educação, da PUCSP. Orientadora: Dra. Marli E. D. A. de André. 
de professores e de alunos aparecem em 38\% dos trabalhos apresentados, como resultado de investigações no contexto de sala de aula, em pesquisas bibliográficas e documentais.

Quanto às instituições de procedência dos trabalhos, a grande maioria origina-se dos programas de pós-graduação dasuniversidades públicas e das privadas confessionais.

No contexto dos Grupos de Trabalho da ANPEd (GTs), os trabalhos analisados têm a seguinte distribuição:
GT (4) Didática - 20
GT (8) Formação de Professores - 27
GT (11) Políticas de Educação Superior - 55
GT (16) Educação e Comunicação - 10
GT (19) Educação Matemática - 16

Dos outros GTs foram analisados entre um e cinco trabalhos, com exceção do GT (6) Educação Popular, no qual, não encontramos nenhuma referência ao nosso objeto de estudo.

Agrupamos os dados organizando-os em seis categorias:

1. Investigação sobre as práticas de ensino aprendizagem em sala de aula;

2. Análises e estudos teóricos sobre cursos, estrutura curricular, disciplinas, áreas de conhecimento;

3. Professores;

4. Alunos;

5. Professores e alunos;

6. Associação entre ensino, pesquisa e extensão.

\section{$1^{\text {a }}$ Categoria}

Nesta categoria incluímos trabalhos que investigam diretamente a sala de aula: metodologias de ensino, ensino com pesquisa, processos de aprendizagem; concepções de alunos e professores sobre aprendizagem ou sobre itens específicos dos conteúdos das disciplinas.

Os métodos de pesquisa utilizados nestes trabalhos envolvem observação direta, por outra pessoa, do trabalho pedagógico realizado em sala de aula; relatos e reflexões de professores acerca dos processos que ocorrem em aula, bem como, investigações realizadas por professores com o objetivo de conhecer as representações e outras concepções de seus alunos.

Nos 26 textos que salientam aspectos das licenciaturas, os cursos mais estudados foram os de pedagogia e de licenciatura em matemática; quanto às disciplinas, mereceram maior atenção as da área pedagógica, especialmente a prática de ensino e o estágio supervisionado. Também encontramos observações sobre práticas que se valem do ensino com pesquisa na formação dos licenciados e investigações sobre concepções e representações de alunos e professores sobre, por exemplo, aprendizagem ou conceitos da área de matemática.

Nos vinte e dois trabalhos que salientam aspectos do bacharelado, os cursos que tiveram maior destaque foram os de engenharia e matemática; entre as disciplinas, as de matemática e cálculo. As investigações sobre o uso de tecnologias da informação e da comunicação como ferramentas de ensino e de aprendizagem e as diversas concepções e representações de professores e de alunos receberam maior ênfase.

Computados os cursos de licenciatura e os de matemática e engenharia, são raras as apresentações de trabalhos sobre práticas de ensino-aprendizagem em outros cursos; isto não quer dizer que esse tipo de investigação não exista, mas que, pode estar sendo veiculada em outros fóruns.

Ao todo, dos quarenta e oito trabalhos que relatam práticas de ensino-aprendizagem em sala de aula, nas licenciaturas e bacharelados, vinte trabalhos se referem ao ensino de ciências, biologia e matemática.

É interessante salientar, que os anos em que foram apresentados mais trabalhos deste tipo foram 2001 e 2002, provavelmente como repercussão da ênfase dada às práticas nas Diretrizes Curriculares para o Ensino Superior e das experiências de ensino com tecnologia virtual de informação e comunicação.

\section{$2^{\text {a }}$ Categoria}

Esta categoria agrupa estudos teóricos realizados com base em análise bibliográfica e 
documental e que tem como tema a estrutura curricular, a organização de cursos e de conteúdos disciplinares, entre outros, e, a constituição histórica de cursos, conteúdos, disciplinas ou áreas de conhecimento.

Dos quarenta trabalhos incluídos nesta categoria, trinta abordam questões relacionadas aos cursos de formação de professores e dez aos cursos de bacharelado.

O destaque entre os cursos é, novamente, para o de pedagogia. Entre as disciplinas, o destaque é para as da área pedagógica, entre elas, didática, avaliação, educação infantil e filosofia da educação. Discute-se a disciplina como campo de investigação, sua importância, abrangência e constituição.

Outros trabalhos têm como tema aspectos da formação inicial e continuada do professor. Seis trabalhos ressaltam aspectos da diferenciação entre o bacharel especialista e o professor licenciado formados em cursos de educação ambiental, história e ciências biológicas, situação que decorre, provavelmente, da desarticulação entre o ensino e a pesquisa presente na estrutura curricular desses cursos.

Nesta categoria, também foram apresentados maior número de trabalhos nos anos de 2001 e 2002. Isto se deve, provavelmente, à análise das repercussões da política de avaliação nacional de cursos do ensino superior e ao impacto das Diretrizes, que levaram a reformulações curriculares.

\section{$3^{\mathrm{a}}$ e $4^{\mathrm{a}}$ Categorias}

Nestas categorias, incluímos os trabalhos que salientam aspectos relacionados aos alunos de graduação e às relações entre alunos e professores. Apenas onze trabalhos investigaram questões relativas aos alunos de graduação e somente dois traçaram qualquer relação entre professores e alunos.

Em relação aos alunos de graduação, os aspectos que mereceram maior destaque estão relacionados aos problemas de acesso e permanência, à evasão e ao fracasso escolar no nível superior. Outros trabalhos investigam práticas de leitura e buscam caracterizar a população discente, principalmente no aspecto sócio-econômico. Dois textos abordam aspectos que envolvem professores e alunos: o primeiro busca conexões entre o ingresso e a permanência dos alunos e o incentivo à pesquisa e à dedicação exclusiva dos professores e, o segundo, aborda questões de assédio moral.

\section{$5^{\text {a }}$ Categoria}

Os trabalhos sobre professores de ensino superior aumentam ao longo do período investigado, totalizando 26 trabalhos em 2003. A maior ênfase foi dadaà investigação dos aspectos relacionados à formação e às práticas docentes, em especial, ao ensino com pesquisa; outros temas que aparecem em relação ao professor de ensino superior são: suas concepções e representações e questões de identidade, raça e gênero. Também são investigados temas como a formação inicial e continuada e a operacionalização para a docência e a avaliação do trabalho docente e de aprendizagem.

\section{$6^{\text {a }}$ Categoria}

Nesta categoria foram incluídos trabalhos que contribuem para a compreensão das funções institucionais de ensino e de pesquisa, especialmente nas universidades, e a relação com a graduação.

A discussão da relação entre ensino e pesquisa está inserida em trinta e seis trabalhos que analisam a história, o financiamento, a estrutura, a diversidade institucional ou a organização da educação superior brasileira. A despeito da diversidade temática desses trabalhos, todos fazem a defesa do ensino aliado à pesquisa, ou melhor, da indissociabilidade entre ensino e pesquisa como condição para a qualidade da formação nesse nível educacional, seja na pesquisa que faz parte das atividades desenvolvidas com os alunos, seja na atividade e constituição do professor como pesquisador.

Essa posição vem ao encontro da análise crítica da qualidade do ensino superior realizado em instituições onde nem professores 
nem alunos fazem pesquisa. Isto vale para a realidade das instituições privadas e públicas. Os trabalhos analisados nesta categoria mostram uma situação na qual, a maioria dos alunos de graduação no ensino público pouco ou nada entra em contato com a pesquisa que por ventura é realizada na instituição. O que fica evidente nesses trabalhos apresentados na ANPEd é que no ensino de graduação prevalecem um modelo de ensino transmissivo e uma idéia de conhecimento estático.

Diversos fatores contribuem para essa situação. Entre outros, os fatores mais mencionados são: uma estrutura didática que relaciona ensino à graduação e pesquisa à pósgraduação; políticas governamentais atuais de financiamento e incentivo à pós-graduação; estímulo financeiro e prestígio acadêmico para professores produtivos na pós-graduação; a expansão de um ensino sem pesquisa que oferece cursos isolados, nos quais aliam-se conteúdos e tempos aligeirados, resultando em um ensino fútil e superficial. Paralelamente, prevalece uma lógica que privilegia a formação para o mercado de trabalho, paradoxalmente contrária, como vários trabalhos apresentados na ANPEd apontam, a uma formação crítica e reflexiva entendida como a necessária à sociedade do conhecimento, altamente tecnológica.

\section{Análise dos Dados}

Feito o mapeamento dos aspectos da graduação destacados na ANPEd, realizamos uma comparação com alguns trabalhos de síntese da produção acadêmica da área de educação no Brasil (ANDRÉ, 2002; MANCEBO E FÁVERO, 2004; MOROSINI, 2001; ROMANOWSKI, 2002; SEGENREICH, 2001). Dessa comparação, pretendemos salientar os temas objeto de estudo que aparecem como novidade, os que permanecem ou se repetem e os que nos parecem lacunas da construção de conhecimento na área.

Entre os temas que aparecem como novidade, destacam-se os estudos sobre educação ambiental, as análises do impacto da avaliação institucional sobre os cursos de graduação, a preocupação com a formação do professor para o ensino superior (mudanças curriculares e avaliação de cursos) e a incipiente pesquisa sobre as relações entre professores e alunos.

A ANPEd e as análises da literatura educacional (ANDRÉ, 2002; MANCEBO E FÁVERO, 2004; MOROSINI, 2001; ROMANOWSKI, 2002; SEGENREICH, 2001) têm em comum a dispersão de temas e de aspectos focalizados 3 ; a falta de continuidade nas pesquisas; a ênfase nos cursos de licenciatura, em especial a de Pedagogia e a recorrência de pesquisas cujo tema são as disciplinas de estágio e de prática de ensino.

É surpreendente, no período estudado, a ausência de estudos sobre as novas tecnologias de informação e comunicação (NTICs) como instrumentos na formação de professores, tanto na ANPEd quanto nas análises da literatura educacional. Como foi mencionado acima, esse tema de pesquisa esteve mais presente em estudos sobre outros cursos de graduação, em especial, cursos das áreas exatas e tecnológicas como matemática e engenharia.

Temas como a pesquisa institucional sobre alunos e sobre condições de trabalho dos professores de ensino superior apareceram de modo incipiente e o tema professores substitutos foi praticamente ignorado. Algumas lacunas de pesquisa podem ser apontadas em temas como aluno trabalhador, aluno com necessidades especiais, idade de ingresso, orientação vocacional, entre outros; estes temas, como aponta Morosini (2001), aparecem de modo incipiente na literatura educacional.

Embora se defenda a indissociabilidade entre

${ }^{3} \mathrm{O}$ que leva ao aparecimento de temas pontuais ou sazonais como, por exemplo, estudos motivados pelas novas Diretrizes Curriculares, exceto os temas aprofundados por linhas e grupos de pesquisa consolidados. 
ensino e pesquisa como princípio pedagógico, o que se nota em muitos trabalhos é a falta de definição dos termos e de discussão mais aprofundada sobre o significado dessa relação e a sua efetivação na prática, ausência de discussão já apontada por Segenreich (2001).

Os trabalhos cujo tema é a formação do professor para o ensino superior, de modo geral, licenciatura ou bacharelado, aumentaram ao longo do período estudado. É interessante ressaltar que este tema aparece como quase silenciado em teses e dissertações, no estado da arte sobre formação de professores no Brasil realizado por André (2002), o que não acontece na literatura veiculada em periódicos nacionais, como mostra Mancebo (2004).

De modo geral, consideramos promissor o fato de que durante o período estudado, o interesse na graduação foi crescente; isto pode ser constatado pelo aumento do número de pesquisas de 1996 a 2003 e pelo fato de que, praticamente, duplicam no final do período. Podemos concluir que o campo da graduação como tema de pesquisa é praticamente inexplorado e aberto ainda para estudos que objetivem suprir as lacunas e carências apontadas, bem como desvelar aspectos ainda não abordados.

\section{Referências Bibliográficas}

ANDRÉ, M. E. D. A. Formação de professores no Brasil (1990 - 1998). Brasília - DF: MEC/ INEP/ COMPED, 2002.

MANCEBO, D; FÁVERO, M. L. A. (orgs.). Universidade: políticas, avaliação e trabalho docente. São Paulo: Cortez, 2004.

MINDAL, C. B. M. A graduação nos trabalhos da ANPEd (1996 - 2003). Tese de Doutorado. São Paulo: PUCSP - Programa de Estudos Pós-Graduados em Educação: Psicologia da Educação, 2006.

MOROSINI, M. C. Educação superior em periódicos nacionais (1968 - 1995). Brasília - DF: MEC/ INEP/COMPED, 2001.

ROMANOWSKI, dos anos 90. J. P. As licenciaturas no Brasil: um balanço das teses e dissertações. Tese de Doutorado. São Paulo: FEUSP, 2002.

SEGENREICH, S. C. D. relação ensino de graduação e pesquisa: políticas públicas e realidade institucional. In : SGUISSARDI, V.; SILVA, JR. J. R. (orgs.). Educação superior: análise e perspectivas de pesquisa. São Paulo: Xamã, 2001. 